\title{
An Investigation on the Adoption of Electronic Commerce Systems for the Operators of Construction Companies
}

\author{
Nafisa Bello Issa ${ }^{1} \&$ Angela Siew Hoong Lee ${ }^{1}$ \\ ${ }^{1}$ Department of Computing and Information Systems, Sunway University, Malaysia \\ Correspondence: Department of Computing and Information Systems, Sunway University, Malaysia. E-mail: \\ Nafisa.i@imail.sunway.edu.my; angelal@sunway.edu.my
}

Received: January 7, 2020

Accepted: March 12, 2020 Online Published: April 10, 2020

doi:10.5430/jbar.v9n1p9

URL: https://doi.org/10.5430/jbar.v9n1p9

\begin{abstract}
E-commerce is emerging and growing in all kinds of businesses and industries over the world especially in the construction industry. This research focuses on the adoption of business-to- business kind of e-commerce in construction industry. This research aims to identify the motivational and barrier factors of the construction workers in influencing the adoption of e- commerce specifically in the construction industry world. As part of the research, a multinational company, which produces tools for the construction industry, will be used as a case study to look into how the customers of this company are adopting e-commerce. This research uses the Diffusion of Innovation model as the based research framework to understand the factors that explain the rate of adoption and how these factors are influencing the adoption in the construction industry. Other internal and external factors of companies such as the organizational factor, technological factor digital readiness will also be looked into to understand their influence as well when it comes to adoption of e-commerce. Data collection is done by distributing questionnaires to the related participants in the construction industry. Findings from this study provides insights on the factors of adoption by applying the diffusion of innovation model and recommendation of strategies for this industry to address the problem of low adoption of e-commerce among construction workers in the construction industry. This research showed that relative advantage, compatibility, complexity, Trialability, organizational readiness and trust are significant factors leading to the adoption of e-commerce systems. Culture as well as technological and digital readiness were found to be insignificant. Overall, the study's findings enrich the discourse related to the adoption of e-commerce systems by construction companies in Asia and other parts of the world. The findings will be relevant for construction companies around the world planning to introduce or improve the e-commerce adoption of the customers. The study's findings could also be relevant for future analysis of e-commerce adoption.
\end{abstract}

Keywords: E-commerce, theory of diffusion of innovation, construction, motivational factors, barriers of adoption

\section{Introduction}

The world is becoming more and more used to buying and selling of goods online. "As we enter the 21 st century, business conducted over the Internet (which we refer to as 'e-business'), with its dynamic rapidly growing and highly competitive characteristics, promises new avenues for the creation of wealth" (Amit and Zott, 2001). Companies are now moving on selling goods and service online to keep up with emerging technologies. E-business can be properly defined as "The transformation of an organization's processes to deliver additional customer value through the application of technologies, philosophies and computing paradigm of the new economy" (Khurana et al., 2011). E-business is said to be able to add revenue and sales for companies around the world.

Tian and Stewart (2008) refer to E-Commerce as the transaction of goods and services through electronic communications. It also refers to "any form of business transaction in which the parties interact electronically rather than by physical exchanges or direct physical contact" (Timmers, 1998). Pearson (2000) defined e- commerce as "the use of the Internet and the Web to transact business. More formally, digitally enabled commercial transactions between and among organizations and individuals"

E-Commerce is generally associated with the buying and selling of good and services over the Internet. A more complete definition of E-commerce by Emanuella et al. (2000 cited in Kuppuswamy et al., 2012) is "the use of electronic communications and digital information processing technology in business transactions to create, transform, and redefine relationships for value creation between or among organizations, and between organizations 
and individuals."

B2B is the buying and selling of products and services among businesses. Rania Nemat (2011) described B2B as "commerce transactions between businesses, such as between a manufacturer and a wholesaler, or between a wholesaler and a retailer". B2B is when two businesses exchange product, services or even information with each other. These sales are done in bulks as companies usually buy huge amount of good.

According to Sagehub (2010), Web-based B-to-B includes direct selling and support to business. This means that businesses exchange and support products and services to each other via the web. This aspect of e- commerce is what will be studied in this research.

"Electronic commerce (EC) has the potential to improve efficiency and productivity in many areas and, therefore, has received significant attention in many countries" (Lawrence \& Tar, 2010) However, depending on what kind of industry it is, there is still a problem of adapting to this channel and using it to buy the services provided by the industry. The digital trends of a place, how people there adapt to different online buying activities has a very big impact in the way the sales are being done.

While there are researches that have widely publicized the benefit of e-commerce as well as barriers in different industries, little attention has been given to how the construction industry adopts e-commerce, the barriers they face and how they overcome them (Liu et al., 2015). DIST (1998) discussed how in Australia, business organizations in the construction industry have been slow, perhaps even reluctant, to implement information and communication technologies to support e-commerce while other industries were already implementing e- commerce in their organizations. According to DIST (1998), these factors prevent the adoption of IT in construction;

- Resistance from management

- Tight profit margins which make it difficult to fund investment in an IT infrastructure

- Lack of IT awareness

- Lack of employee education and training

- Degree of organizational change required

- A belief that the industry is doing well without IT

"E-commerce can reduce an organization's costs, particularly across supply chains, improve customer service, create additional revenue streams and create new business relationships. (Love et al., 2001).

In the following section, the conceptual model, literature review and hypotheses development were presented. Subsequently, research methods, model assessment and test hypotheses were presented, followed by the discussion of the findings. Finally, conclusion and policy implications were noted.

\section{Literature Review}

There are various studies on the adoption of e-commerce in different industries, firms or countries. These studies have a variety of focus such as factors influencing the adoption, readiness of countries/firms, challenges, barriers, success factors and a lot of other aspects that influence e-commerce.

A lot of researchers have shown great interest in key factors influencing e-commerce adoption in different parts of the world as well as different industries. A study on the adoption of B2B e-commerce in organizations in Malaysia and found out that factors such as perceive relative advantage, compatibility, managers' characteristics, organizational readiness and security were very significant in predicting an organizations intention to use e-commerce (Shah Alam et al., 2010). Numerous researches have looked into organization factor as one of the factors in adopting e-commerce. The main part of organizational factor is the top management support. The study also mentioned that managers' characteristics are important factors affecting the adoption and utilization of the Web (Shah Alam et al., 2010). "Top management support is critical for successful adoption of new ideas and technologies in organizations" (Luvsanbyamba \& Chung, 2009). From their research, they found out that top management support had a strong positive influence when it comes to adopting and using e-commerce from both the sellers' and buyers' perspective. "This is because when implementing e-commerce, it is generally a long term project and investments are needed to expand the e- commerce operations as it becomes successfully implemented in the company" Luvsanbyamba \& Chung, 2009). Top management recognizes strategic opportunities and provides long-term vision, attributes that are critical for successful adoption of an innovation Quinn, 1985). Research of innovation and adoption by Premkumar et al. (1997) theoretically explains the important relationship between organizational factors and IT adoption. "Whether firms engage in one of the various e-business activities, such as online procurement of 
goods, participation in virtual marketplaces or distribution of goods via an online channel, is significantly influenced by the preparedness of an organization to do so" (Kollmann et al., 2009). On the other hand, there are still existing organizations that do not have any e-commerce or even a website for their company. Another organizational factor that is the financial status of the organization. A study by Lin et al. (2010) found out that most organizations that were interviewed had sufficient management leadership and commitment to adopt e- commerce. However, these organizations also stated that with all the sign off by top management on e- commerce projects, there was almost little or no follow up support from them (AshLee \& Tm Lim, 2015). "They perceived it simply as an IT-enabled cost-cutting mechanism rather than as a central strategic issue for their business" (Lin et al., 2010).

The people in an organization are an important part of the adoption of e-commerce in that organization "Employees and processes need to be ready for an organization to advance in the use of technology" (Rouibah et al., 2009). Ajmal and Yasin (2012) in their research on adoption of e-commerce mention that the proper education, awareness along with IT and expertise of the people in an organization is necessary for adoption of e-commerce. This is because with implementation of all the new techniques, employees will have to change work attitude, qualification, performance as well as their knowledge of e-commerce. A study was carried out by Lin et al. (2010) to investigate B2B adoption and implementation constraints. One of the constraints in their finding was the failure to retain knowledge in the organization. This was due to "high turnover rate of skilled B2B e-commerce operators and also the fact that many of the affected employees were not involved in the early stages of the purchase decision and adoption of B2B e-commerce systems". This clearly shows that in order for an organization to adopt e-commerce, the people who will end up being the operators of this technology needs to be well educated and savvy of the technology.

Technology readiness (TR) refers to "people's propensity to embrace and use new technologies to accomplish goals in home life and at work" (Parasuraman, 2000). Factors such as the User Interface/User Experience (UI/UX) may differ per country or region and lead to whether that country wants to adopt e-commerce. The ease of use of the technology may also be a factor for adoption e-commerce. This factor will focus mainly on understanding if different technological reasons are barriers to adoption. The whole world is now moving to the digital age. Digital readiness can be defined as "the capacity for people to engage with online resources with full information about service attributes and use of personal and household data" (Horrigan, J.B, 2014). It is the level of maturity and knowledge that an individual or firm has to be able to keep up and use existing technologies. There are millions of people who have access to the internet via laptops, smartphones, tablets, etc. but at the same time have not enough level of "digital readiness" to use online applications (Horrigan, 2014).

\subsection{Diffusion of Innovation Theory}

The Diffusion of innovation theory is one of the oldest theories that looks into the adoption of innovation or new ideas/technology. This theory goes far back to 1903 by Gabriel Tarde where it was discussed in his influential book "the laws of imitation" where he observed different generalization about diffusion of innovation. He was the first to study that when a new idea is introduced, the rate of adoption of this idea is usually followed by an s-shaped curve over time. "At first, only a few individuals adopt a new idea, then the rate of adoption spurts as a large number of individuals accept the innovation, and finally the adoption rate slackens" (Rogers, 1983 p. 41) Rogers mentioned 5 factors which explain the different rate of adoption perceived by individuals

I. Relative Advantage: the degree to which an innovation is perceived as better than the idea it supersedes. This talks about the perceived advantage of an innovation meaning it doesn't really matter if this innovation has a great "objective" advantage. What matters even more is how each individual perceives this innovation as advantageous. The higher the relative advantage of an innovation, the higher its rate of adoption is going to be.

II. Compatibility: the degree to which an innovation is perceived as being consistent with the existing values, past experiences and needs of potential adopters.

III. Complexity: the degree to which an innovation is perceived as difficult to understand and use. The more complicated an innovation is, the slower it will be adopted.

IV. Trialability: the degree to which an innovation may be experimented with on a limited basis. When new ideas are introduced by installment and not all at once, they will be more adopted easily.

V. Observability: the degree to which the results of an innovation are visible to others. Individuals care about results therefore if the results are easy for individuals to see, there is more likelihood for adoption. 


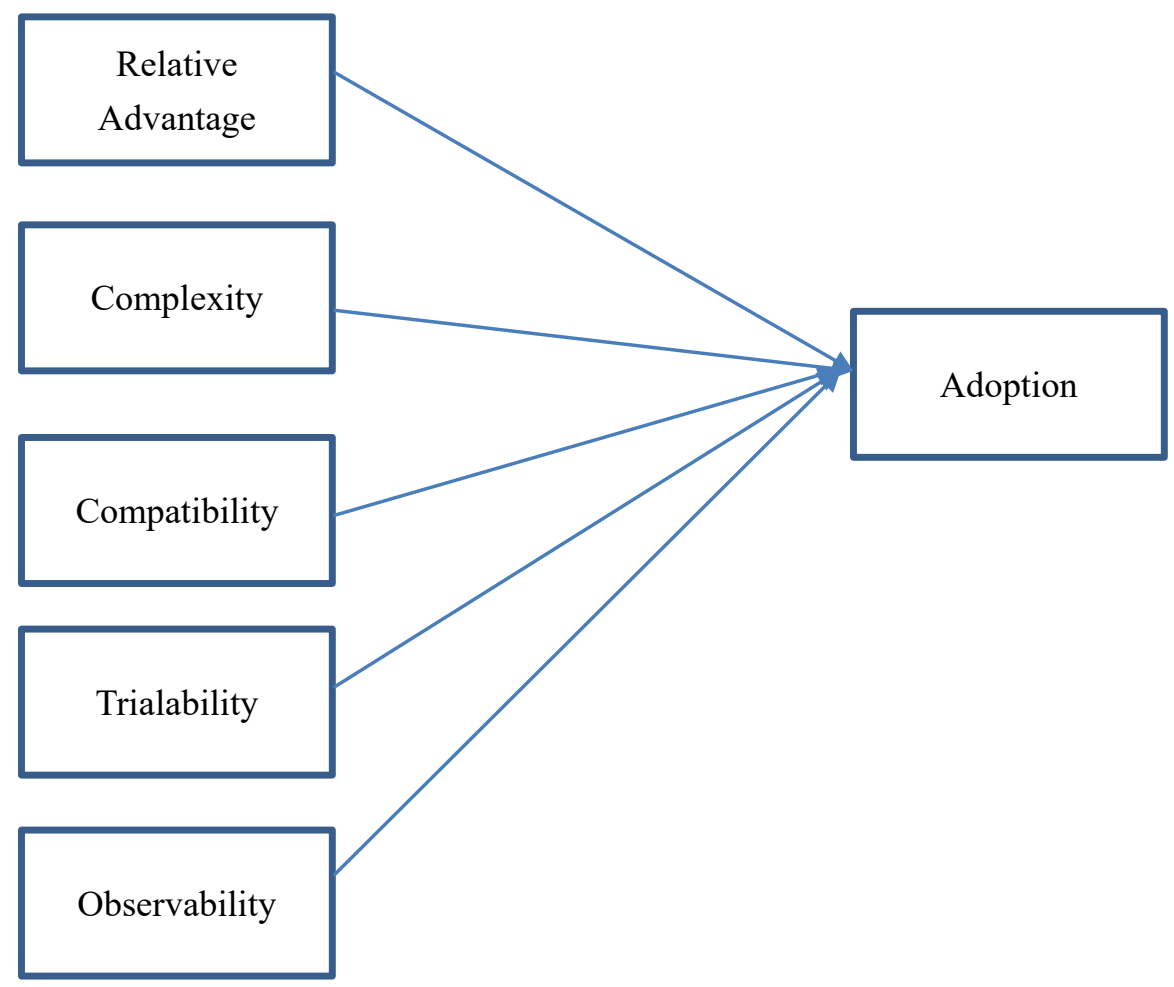

Figure 1. Innovation Diffusion Theory (Rogers, 1995)

The diffusion of innovation theory as explained above has to do with how people are open to and accept new ideas, practices, technologies, etc. Kaminsky (2011) believes this is a very important theory that can serve administrators, information technologists, nursing informatics experts, and change agents well. He also mentioned that "the theory also benefits the targets of change, since respect and consideration for all involved stakeholders is intertwined with robust strategies for implementing innovative change".

This research will be using Diffusion of Innovation theory (DOI) as the foundation and base model. Rogers (1983) defined diffusion as "the process by which an innovation is communicated through certain channels over time among the members of a social system. He also defined innovation as "an idea, practice, or object perceived as new by an individual or other unit of adoption". Zaltman, Duncan \& Holbek (1973) explained further saying the innovation doesn't necessarily mean that it is a new invention or a new discovery but it just has to be seen as new by the organization. Diffusion of Innovation theory has been used in a huge number of technology acceptance researches around the world. Aghaunor et. Al (2006) investigated the factors affecting e-commerce adoption in Nigerian banks using the DOI theory as the base model. The data for research was collected using survey questionnaires and semi-structured interview. In the findings of this research, three of the essential attributes in Roger's theory were discovered to have an affect on the adoption of e-commerce. The three attributes are Relative Advantage, complexity and compatibility. "If e-commerce is viewed as better than the existing method of operations, consistent with the needs of the adopting bank, and is easy to use, then there is a greater chance that a favorable attitude towards ecommerce will be formed" Aghaunor et. Al (2006). Other external factors such as Management support, readiness of the organization, IT capability, etc. were also discovered to have an effect in the adoption of e-commerce. In a descending order of impact, the rank of the factors affecting adoption of ecommerce that was found in this research is: Perceived complexity, Perceived benefits, Organizational competence, Perceived compatibility, Supporting industries e-readiness, Management support, Market e-readiness, IT capability, and Government e-readiness.

From the creation of DOI theory by Roger, it has been used extensively in researches to identify and investigate different factors. The literature shows that the DOI theory has a solid theoretical foundation and consistent empirical support (e.g. Aghaunor et. Al., 2006; Moore and Benbasat, 1991; Vladimir et al., 2017 ; Shah Alam et al.,2010; Zhu 
et al., 2006a). It is a useful theory for studying a variety of information systems (IS) innovations (Moore \& Benbasat, 1991). The attributes of this theory have proven numerous hypothesis and has helped researches in carrying their research. Fichman (2000) mentioned in his research that Roger's classical model of diffusion greatly shaped the basic concepts, terminology, and scope of the field of innovation diffusion. Therefore, this research will also be using this theory as the base model. In addition to the attributes of this theory, after a lot of research has been done on e-commerce adoption, this research also adapts few more constructs in order to fully investigate as well as answer the research questions.

\subsection{Research Questions}

This research would like to get an answer for the following research questions;

1. What are the motivational and barrier factors in the adoption of e-commerce system among construction industry in Asia?

2. In addition to the DOI theory, would additional constructs integrated in the model influence the adoption of e-commerce system?

\subsection{Research Objectives}

This research work is intended to investigate the different reasons and pace at which construction companies adopt e-commerce systems with much focus on Asian countries. In summary, these are the main objectives that are going to be explored throughout this research:

1. To investigate the influence of DOI model with other external factors in influencing the adoption of e-commerce systems.

2. To measure the outcomes of the motivational and barrier factors that influence the adoption of e- commerce systems.

\section{Proposed Research Model}

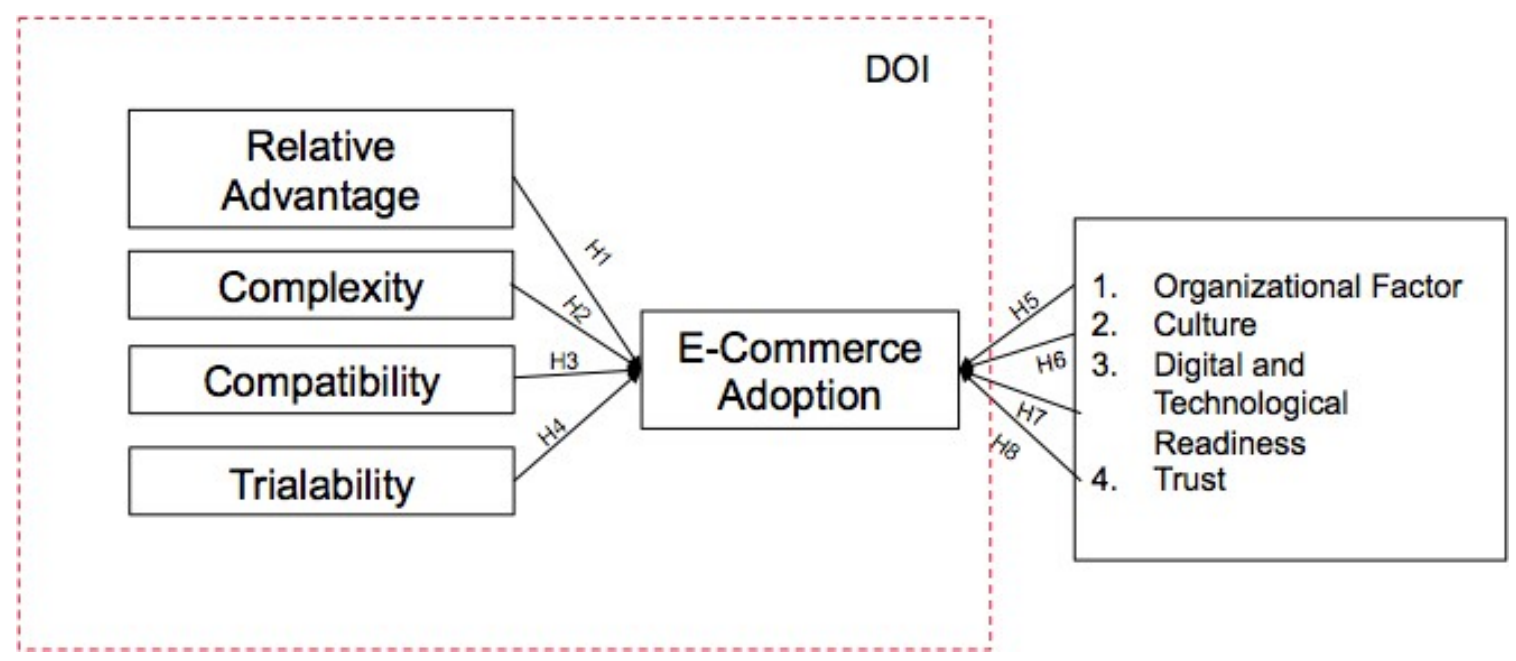

Figure 2. Proposed Research Model

As this research looks into the adoption of e-commerce, factors in this theory have been researched by several authors perceived to have huge influence on the adoption of e-commerce. The theory of diffusion of innovation will be used as the base model for this resaearch. In addition to the factors from the diffusion of innovation theory, more factors will be studied which are also shown in the model. These factors were put into this model where hypothesis were formed. Below are the list of hypothesis:

Hypothesis 1: Relative Advantage has a positive influence on the adoption on e-commerce system Hypothesis 2: Complexity has a negative influence on the adoption on e-commerce system Hypothesis 3: Compatibility has a positive influence on the adoption on e-commerce system Hypothesis 4:Trialability has a positive influence on the adoption on e-commerce system Hypothesis 5: Organizational factor has a positive influence on the adoption on 
e-commerce system Hypothesis 6: Culture has a positive influence on the adoption on e-commerce system

Hypothesis 7: Digital and Technological Readiness has a positive influence on the adoption on e-commerce system Hypothesis 8: Trust have a positive influence on the adoption on e-commerce system.

\subsection{Research Methodology}

The main data collection technique that will be used during this research will be questionnaires. "A questionnaire is simply a 'tool' for collecting and recording information about a particular issue of interest. It is mainly made up of a list of questions, but should also include clear instructions and space for answers or administrative details" (Kirklees, 2014). "A questionnaire is simply a 'tool' for collecting and recording information about a particular issue of interest. It is mainly made up of a list of questions, but should also include clear instructions and space for answers or administrative details" (Kirklees, 2014).The overall population for this questionnaire will be the customers from different countries of the case study company that will be used which are Singapore, Australia and United Kingdom. It is a multinational company, which has an online portal for construction companies to acquire the products and services of that company. In each country, three smaller samples will be created which are customers with high usage of the e-commerce platform, customer with low usage and customers that do not use it at all. From each of these groups or subpopulations, a particular number will be selected randomly. With this questionnaire, the voices of these customers with different levels of maturity can be heard and also relevant information regarding how or if they use e-commerce with the barriers and reasons why they are either progressing with this channel or not.

The first part of the questionnaire will be used to collect basic information of the respondents will be collected such as gender, age and company location. The rest of the questionnaire will be designed using a likert scale. A Likert scale gives the respondents options where they choose which one best supports their opinion. A 5-point likert scale will be used where the options given will be; strongly agree, agree, neutral, disagree and strongly disagree. These will be used for all the questions under each construct of the questionnaire.

\section{Results and Analysis}

There was a total of 264 responses from the survey. $55 \%$ of the respondents were male while $45 \%$ were female. From the three (3) chosen countries for this research, there were 88 respondents from Australia, 84 from Singapore and 92 from the United Kingdom. In terms of age group, 10\% were from the 20-29 range, 25\% from the 30-39 range, $36 \%$ from the $40-49$ range, $23 \%$ from the 50-59 range and 6\% from the 60-69 range. The figure below summarizes the demographic analysis of respondents

Table 1. Demographic analysis of respondents

\begin{tabular}{lll}
\hline Profile & Frequency & Percentage (\%) \\
\hline Gender Male Female & 144 & 55 \\
& 120 & 45 \\
\hline Age & & \\
$20-29$ & 28 & 10 \\
$30-39$ & 67 & 25 \\
$40-49$ & 94 & 36 \\
$50-59$ & 60 & 23 \\
$60-69$ & 15 & 6 \\
\hline Country Australia Singapore & 88 & 33 \\
United Kingdom & 84 & 32 \\
& 92 & 35 \\
\hline
\end{tabular}

For analysis of this research, Partial Least Square Structural Equation Modeling (PLS-SEM) was used to analyze the proposed model. PLS-SEM is a causal modeling approach aimed at maximizing the explained variance of the dependent latent constructs (Hair, Ringle and Sarstedt, 2011). Path models are referred to as diagrams that are used during PLS SEM analysis to show the relationships and hypothesis being examined. A PLS path model has two 
elements which are the structural model as well as the measurement model. The measurement model, also known as the outer model is a rectangle diagram that displays the relationship between the constructs and its variables. PLS SEM has two ways of measuring variables. The reflective measurement model is when a construct causes the measurement of the indicator variables while the formative measurement model is when the indicator variables are the cause of the construct.

Composite reliability examines reflective construct's internal consistency for the research while cronbach's alpha measures reliability by provide an estimate of the reliability based on the intercorrelations of the observed indicator variables (Hair et al., 2016). Both measurements vary between 0 and 1; the higher the value, the higher the level of reliability. A value of $0.60-0.70$ is said to be acceptable which values between 0.70 and 0.90 are deem satisfactory (Hair et al., 2016).

Table 2. Composite reliability analysis

\begin{tabular}{lll}
\hline Construct & Composite Reliability & Cronbach's Aplha \\
\hline Adoption & 0.837 & 0.707 \\
\hline
\end{tabular}

In this study, there was a composite reliability of 0.837 and cronbach's alpha of 0.707 which indicates a high level of reliability.

In assessing the convergent validity of constructs, indicator reliability was considered. Indicator reliability is the size of the outer loading and is gotten from the square value of the outer loading. A standard outer loading for indicator reliability must be more than 0.708 .

Table 3. Summary of Indicator Reliability

\begin{tabular}{lll}
\hline Construct & Items & Indicator Reliability \\
\hline \multirow{3}{*}{ Adoption } & AD1 AD2 AD3 & 0.753 \\
& & 0.323 \\
& 0.820 \\
\hline
\end{tabular}

\subsection{Assessment of the Formative Measurement Model}

There are ways that the significance and relevance of formative items can be measured. These three ways are the outer loadings, the outer weights and the t-values. Hair et al., (2010) describe outer weight as the "result of a multiple regression with the latent variable scores as the dependent variable and the formative indicators as the independent variables." The outer loading is also carried out to assess significance and relevance. Outer loading is also considered as the formative indicator's absolute contribution as it is the information that on indicator provides independently without any other indicator. In order for the items to be relevant for this research, its must have either the other weight below the maximum weight or the outer loading should be more than 0.5 .

Bootstrapping is used to test coefficients for their significance. What bootstrapping does is that it draws a large number of samples from the original sample with replacement. These samples are used to estimate the PLS path model. According to Hair et al. (2010), the critical t-values for significant level of $5 \%$ (alpha $=0.05$; two- tailed test) is 1.96 while the critical t-values for significance levels of $1 \%$ (alpha $=0.01$; two-tailed test) and $10 \%$ (alpha $=0.10$; two-tailed test) probability of error are 2.57 and 1.65 respectively. The t-value is checked to see if the item is significant. Outer loading and outer weight are also checked respectively to see if the criteria have been fulfilled. In this research, the significance level of $10 \%$ will be used in measuring the $t$-value. Therefore, the first thing that will be checked is if the t-value of each item is $>1.65$. For items that do not meet this criteria, outer loadings of those items will be checked to examine whether is is $>0.50$.T able 4 shows the results, which indicate all items, were retained as they pass one or both criteria's mentioned above. 
Table 4. Items in each constructs

\begin{tabular}{|c|c|c|c|c|c|}
\hline Construct & Items & Outer Weight & Outer Loading & Max Weight & $\begin{array}{l}\text { T- } \\
\text { Value }\end{array}$ \\
\hline & RA1 & 0.048 & 0.805 & 0.5 & 0.461 \\
\hline Relative & RA2 & 0.427 & 0.920 & & 4.405 \\
\hline \multirow[t]{2}{*}{ Advantage } & RA3 & 0.157 & 0.877 & & 1.390 \\
\hline & RA4 & 0.466 & 0.924 & & 4.228 \\
\hline \multirow{3}{*}{ Compatibility } & $\mathrm{CO} 1$ & 0.312 & 0.871 & 0.577 & 4.779 \\
\hline & $\mathrm{CO} 2$ & 0.575 & 0.947 & & 7.420 \\
\hline & $\mathrm{CO} 3$ & 0.207 & 0.883 & & 2.902 \\
\hline \multirow{3}{*}{ Complexity } & COMPLEX1 & -0.084 & -0.556 & 0.577 & 1.098 \\
\hline & COMPLEX2 & 0.639 & 0.908 & & 7.456 \\
\hline & COMPLEX3 & 0.458 & 0.814 & & 5.429 \\
\hline \multirow{3}{*}{ Trialability } & TR1 & 0.810 & 0.967 & 0.577 & 7.805 \\
\hline & TR2 & 0.292 & 0.725 & & 1.581 \\
\hline & TR3 & 0.008 & 0.576 & & 0.042 \\
\hline \multirow{6}{*}{$\begin{array}{l}\text { Organizational } \\
\text { Factor }\end{array}$} & OR1 & 0.407 & 0.818 & 0.408 & 3.155 \\
\hline & OR2 & 0.092 & 0.743 & & 0.554 \\
\hline & OR3 & 0.294 & 0.819 & & 2.030 \\
\hline & OR4 & -0.038 & 0.663 & & 0.279 \\
\hline & OR5 & 0.411 & 0.837 & & 3.076 \\
\hline & OR6 & -0.120 & -0.322 & & 1.542 \\
\hline \multirow{6}{*}{ Culture } & CU1 & 0.623 & 0.878 & 0.408 & 5.918 \\
\hline & CU2 & -0.094 & 0.425 & & 0.733 \\
\hline & CU3 & 0.265 & 0.634 & & 2.514 \\
\hline & CU4 & 0.301 & 0.687 & & 2.363 \\
\hline & CU5 & -0.025 & -0.332 & & 0.178 \\
\hline & CU6 & 0.230 & 0.477 & & 2.251 \\
\hline \multirow{3}{*}{$\begin{array}{l}\text { Technological \& Digital } \\
\text { Readiness }\end{array}$} & TDR1 & 0.805 & 0.967 & 0.577 & 7.234 \\
\hline & TDR2 & -0.022 & -0.604 & & 0.173 \\
\hline & TDR3 & 0.291 & 0.715 & & 1.889 \\
\hline \multirow{3}{*}{ Trust } & TRUST2 & 0.199 & 0.896 & 0.577 & 0.867 \\
\hline & TRUST3 & 0.334 & 0.945 & & 0.882 \\
\hline & TRUST4 & 0.577 & 0.967 & & 1.273 \\
\hline
\end{tabular}

\subsection{Assessment of the Structural Model}

After going through all construct measures and finding them valid and reliable, the next step is the assessment of the structural model results by looking at the predictive capabilities as well as the relationship between the constructs.

In order to assess the collinearity, same measures as the ones using in evaluating the formative models will be used. These measure include the tolerance (TL) as well as the VIF values. Tolerance value below 0.2 or VIF values above 5.00 are considered critical levels of collinearity. The table above shows no collinearity issues as all values are below the VIF threshold of 5.0. 
The hypothesized relationships among the constructs also call oath coefficients are obtained for the structural model relationship. The path coefficient has a standard values between -1 and +1 . The closer they are to +1 , the stronger and more positive the relationship is. Also, the closer the coefficients are to 0 , the weaker the relationship. The bootstrap standard error is used to find out the $t$ values and $p$ values for all structural path coefficients with the critical value of 1.6 (significance level $=10 \%$ ). $\mathrm{P}$ values are also used to evaluate significance levels. Hair et al., describe a $\mathrm{P}$ value as a value that is "equal to the probability of obtaining a $t$ value at least as extreme as the one that is actually observed, conditional on the null hypothesis being supported."

A bootstrapping procedure of 5000 samples in order to get the t-values an p-values in this research. Most of the constructs correlate with each other significantly except two constructs. The first one is culture which had a p-value of 0.521 and a t-value of 0.642 . The second is Technological \& Digital Readiness with a p-value of 0.342 and t-value of 0.950 .

Table 5. P-value analysis

\begin{tabular}{lllllc}
\hline Construct & $\begin{array}{l}\text { Collinearity } \\
\text { Analysis }\end{array}$ & $\begin{array}{l}\text { Path } \\
\text { Coefficient }\end{array}$ & T-Value & P-Value & $\begin{array}{c}\text { Significance } \\
\text { Level }\end{array}$ \\
\hline Relative Advantage & 3.118 & 0.2232 & 3.556 & 0.000 & $* * *$ \\
Compatibility & 3.686 & 0.5303 & 9.469 & 0.000 & $* * *$ \\
Complexity & 2.603 & 0.0894 & 1.881 & 0.060 & $*$ \\
$\begin{array}{l}\text { Trialability } \\
\text { Organizational Readiness }\end{array}$ & 1.618 & -0.0762 & 1.956 & 0.050 & $* *$ \\
$\begin{array}{l}\text { Culture } \\
\text { Technological \& Digital }\end{array}$ & 1.008 & 0.1728 & 3.574 & 0.000 & $* * *$ \\
Readiness & 1.878 & 0.0291 & 0.809 & 0.418 & NS \\
Trust & & 0.0474 & 1.153 & 0.249 & NS \\
\hline
\end{tabular}

Note. $\mathrm{NS}=$ Non Significant; ${ }^{*} \mathrm{p}<0.10 * * \mathrm{p}<0.05 * * * \mathrm{p}<0.01$

The path coefficient is only supported when there is a significant t-value. Therefore, out of eight (8) hypothesis, six (6) were supported and two (2) were not supported in this research.

Table 6. Hypothesis testing result (Supported)

\begin{tabular}{ll}
\hline Hypothesis & Decision \\
\hline H1: Relative Advantage has a positive influence on the adoption on e-commerce system & $\begin{array}{l}\text { Supported } \\
\text { H2: Complexity has a negative influence on the adoption on }\end{array}$ \\
$\begin{array}{l}\text { e-commerce system } \\
\text { H3: Compatibility has a positive influence on the adoption }\end{array}$ & Supported \\
$\begin{array}{l}\text { on e-commerce system } \\
\text { H4: Trialability has a positive influence on the adoption on e-commerce system }\end{array}$ & Supported \\
H5: Organizational factor has a positive influence on the adoption on & Supported \\
$\begin{array}{l}\text { e-commerce system } \\
\text { H8: Trust have a positive influence on the adoption on e-commerce system. }\end{array}$ & Supported \\
\hline
\end{tabular}


Table 7. Hypothesis testing result (Not Supported)

\begin{tabular}{ll}
\hline Hypothesis & Decision \\
\hline H6: Culture has a positive influence on the adoption on e-commerce system & Not Supported \\
H7: Digital and Technological Readiness has a positive influence on the adoptionNot Supported \\
on e-commerce system
\end{tabular}

The coefficient of determination is one of the most commonly used measure to evaluate structural model. "This coefficient is a measure of the model's predictive power and is calculated as the squared correlation between a specific endogenous construct's actual and predicted values" (Hair et al., 2016).

The value for R2 is between 0 and 1 . The higher the value, the higher the level of predictive accuracy. A value of 0.75 and above is expected.

Table 8. R2 result

\begin{tabular}{ll}
\hline Construct & $\mathrm{R} 2$ \\
\hline Adoption & 0.830
\end{tabular}

Note. $0.25=$ weak; $0.50=$ medium; $0.75=$ substantial.

\subsection{Limitation and Future Research}

This research accomplished all its objectives as well as research questions. However, as to all researches, there were limitations identified for the research. The first limitation is that this research focuses on three countries in different regions to find out information about e-commerce adoption. Even though excessive information was acquired from these three countries, adding other countries in the future will provide avenue for even more information to be acquired. Secondly, the only source of data collection of this research was questionnaire, which was used during analysis. To further engage the respondents, future research should increase the sample size as well as add other types of data collection such as interviews with both top management as well as lower level staff, which can give future researches even more information on the factors affecting adoption. Lastly, the base model used for this research is the DOI model. In addition to this, other constructs were added based on past researches, which further helped in achieving the objectives of this research. However, there are some additional constructs, which could be looked into more in-depth for even better results. Constructs such as culture can be looked into more.

\section{Conclusion}

This aim for this research was to identify the motivational factors as well as barriers in adopting electronic commerce systems by the operators on construction companies. DOI model as well as other additional constructs was used to carry out this investigation. This research showed that relative advantage, compatibility, complexity, Trialability, organizational readiness and trust are significant factors leading to the adoption of e- commerce systems. Culture as well as technological and digital readiness was found to be insignificant. Overall, the study's findings enrich the discourse related to the adoption of e-commerce systems by construction companies in Asia and other parts of the world. The findings will be relevant for construction companies around the world planning to introduce or improve the e-commerce adoption of the customers. The study's findings could also be relevant for future analysis of e-commerce adoption. It is hoped that the discussions and conclusions presented in this study helps the case study company as well as other companies that sell products online to construction companies. Most importantly, this study contributes to the ever growing knowledge pool about factors influencing the adoption of electronic commerce systems by not just the construction industry but multiple industries across the world.

\section{References}

Aghaunor, L., Fotoh, X., \& Lindh, J. (2006). Factors Affecting Ecommerce adoption in Nigerian Banks. Retrieved from https://pdfs.semanticscholar.org/4bf5/8464e96f6c72d56b8ca4d7edf3488ae60544.pdf

Ajmal, F., \& Yasin, A. (2012). Model for Electronic Commerce Adoption for Small and Medium Sized Enterprises. International Journal of Innovation, Management and Technology, 3(2), 90-94. https://doi.org/10.7763/IJIMT.2012.V3.203 
Amit, R., \& Zott, C. (2001). Value Creation in E-Business [e-book]. https://doi.org/10.1002/smj.187

Angela S., Lee, H., \& Lim, T. (2015). A study on the perception of POKM as the organizational knowledge sharing enabler. VINE, 45(2), 292-318. https://doi.org/10.1108/VINE-09-2013-0052

Definition adapted and expanded from Emmanuel Lallana, Rudy Quimbo, Zorayda Ruth Andam, ePrimer: An Introduction to eCommerce (Philippines: DAI-AGILE, 2000)

Department of Industry, Science and Tourism. (1998). Building for Growth: A Draft Strategy for the Building and Construction Industry, Department of Industry, Science and Tourism, Canberra, Commonwealth of Australia.

Examiner.com. (2014). Interview types: Structured, semi-structured, and unstructured. [online] Available at: $\mathrm{http} / / / \mathrm{www}$.examiner.com/article/interview-types-structured-semi-structured-and- unstructured [Accessed: 20 Mar 2014].

Fichman, R. (2000). The Diffusion and Assimilation of Information Technology Innovations.

Hair, J. F., Ringle, C. M., \& Sarstedt, M. (2011). PLS-SEM: Indeed a Silver Bullet. Journal of Marketing Theory and Practice, 19(2), 139-152. https://doi.org/10.2753/MTP1069-6679190202

Hair, J. F., Black, W. C., Babin, B. J., \& Anderson, R. E. (2010). Multivariate Data Analysis (7th ed.), Pearson, New York.

Hair, J. F., Hult, G. T. M., Ringle, C., \& Sarstedt, M. (2016). A Primer on Partial Least Squares Structural Equation Modeling (2nd ed.). https://doi.org/10.15358/9783800653614

Horrigan, J. (2014). Digital Readiness: Nearly one-third of Americans lack the skills to use next- generation "Internet of Things" applications (1st ed.). [ebook] Retrieved 2 Aug. 2015, from http://jbhorrigan.weebly.com/uploads/3/0/8/0/30809311/digital_readiness.horrigan.june2014.pdf

http://www.sagepub.com/upm-data/9598_019964Ch1.pdf/page 3 -29

Ilin, V., Ivetić, J., \& Simić, D. (2017). Understanding the determinants of e-business adoption in ERP-enabled firms and non-ERP-enabled firms: A case study of the Western Balkan Peninsula. Technological Forecasting and Social Change, 125, 206-223. https://doi.org/10.1016/j.techfore.2017.07.025

Kaminski, J. (2011). Theory in nursing informatics column. Canadian Journal of Nursing Infomatics, 6(2), 1-7.

Khurana, H., Kr. Goel, M., Singh, H., \& Bhutani, L. (2011). E-Commerce : Role of E-Commerce in Today's Business. VSDR International Journal of Business \& Management Research, 1(7).

KIrklees Council. (2014). Research \& Consultation Guidelines. Retrieved 31 Mar, 2014, from http://www.kirklees.gov.uk/community/yoursay/Questionnaires.pdf

Kollmann, T., Kuckertz, A., \& Breugst, N. (2009). Organizational readiness and the adoption of electronic business: The moderating role of national culture in 29 European countries. ACM SIGMIS Database: the DATABASE for Advances in Information Systems, 40(4), 117-131. https://doi.org/10.1145/1644953.1644961

Kuppuswamy, P., \& Mohammed, P. (2012). E-Commerce Security using New Public Key Algorithm based on Block Cipher. International Journal of Computer Science Engineering \& Technology, 2(10).

Lawrence, J. E., \& Tar, U. A. (2010). Barriers to e-commerce in developing countries. Information, society and justice journal, 3(1), 23-35.

Liu, E., Lee, A., \& Lim, T. M. A Case Investigation for a Construction Trading Organization: Enterprise Knowledge. Second International Conference on Innovation and Sustainability, Proceeding ICOIS, 2015.

Lin, C., Huang, Y. A., Jalleh, G., Liu, Y. C., \& Tung, M. L. (2010). An exploratory study of factors affecting adoption and implementation of B2B e-commerce in Australian health care organizations. International Journal of Electronic Commerce Studies, 1(2), 77-96.

Love, P., Cheng, E., Li, H., \& Irani, Z. (2001). An e - business model to support supply chain activities in construction. Logistics Information Management, 14(1/2), 68-78. https://doi.org/10.1108/09576050110363239

Luvsanbyamba, M., \& Chung, I. (2009). An Empirical Study of Success Factors on Business-to- Business E-Marketplaces From Buyers and Sellers Perspectives. In: Proceedings of the 2nd International Conference on Interaction Sciences: Information Technology, Culture and Human (pp. 486-491). https://doi.org/10.1145/1655925.1656014

Moore, G. C., \& Benbasat, I. (1991). Development of an instrument to measure the perceptions of adopting an 
information technology innovation. Information systems research, 2(3), 192-222. https://doi.org/10.1287/isre.2.3.192

Nemat, R. (2011). Taking a look at different types of e-commerce. World Applied Programming, 1(2), 100-104.

Parasuraman, A. (2000). Technology Readiness Index (Tri): A Multiple-Item Scale to Measure Readiness to Embrace New Technologies. Journal of Service Research, 2(4), 307-320. https://doi.org/10.1177/109467050024001

Premkumar, G., Ramamurthy, K., \& Crum, M. (1997). Determinants of EDI adoption in the transportation industry. European Journal of Information Systems, 6(2), 107-121. https://doi.org/10.1057/palgrave.ejis.3000260

Quinn, J. B. (1985). Managing innovation: controlled chaos. Harvard Business Review, 63(3), 73-84.

Rogers, E. M. (1983). Diffusion of innovations. New York: Free Press

Rouibah, K., Khalil, O., \& Hassanien, A. (2009). Emerging markets and e-commerce in developing economies. Hershey, PA: Information Science Reference. https://doi.org/10.4018/978-1-60566-100-1

Shah Alam, S., Ali, M., \& Mohd, J. M. (2011). An Empirical Study of Factors Affecting Electronic Commerce Adoption among SMEs in Malaysia. TBEM, 12(2), 375-399. https//doi.org/10.3846/16111699.2011.57674

Tian, Y., \& Stewart, C. (2008). History of E-Commerce.

Timmers, P. (1998). Business Models for Electronic Markets. Electronic Markets, 8(2), 3-8. https://doi.org/10.1080/10196789800000016

Zaltman, G., Duncan, R., \& Holbeck, J. (1973). Innovation and Organizations (45-68). John Wiley, New York.

Zhu, K., Dong, S., Xu, S., \& Kraemer, K. (2006). Innovation diffusion in global contexts: Determinants of post-adoption digital transformation of European companies. European Journal of Information Systems, 15. 601-616. https://doi.org/10.1057/palgrave.ejis.3000650 